\title{
Entre o risco e a leveza - dois poetas brasileiros contemporâneos
}

VERA LINS ${ }^{I}$

Aujourd'hui ou sans présumer de l'avenir qui sortira d'ici, rien ou presque un art, reconnaissons aisément que la tentative participe, avec imprévu, de poursuites particulières et chères à notre temps, le vers libre et le poème em prose.

(Mallarmé: prefácio a Um lance de dados)

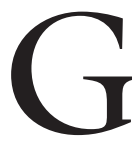
OSTARIA de apresentar aqui dois poetas contemporâneos com cujos textos tenho trabalhado. Do primeiro, Carlos Ávila, pode-se ver a poesia do seu novo livro Área de risco como uma arte do Não. Como dizem os versos finais do poema "Este é o céu":

este é o meu

impossível

canto-calado

para ninguém

(Ávila, 212, p.51)

Enrique Vila-Matas (2010) escreveu um romance ensaio, Bartleby e companbia, retomando escritores que trabalham nessa zona entre a impossibilidade, a insuficiência e a invenção. Temos na poesia brasileira "O sobrevivente", de Drummond, que, negando a possibilidade de fazer poesia depois de 1914, se descobre um poema, apesar de tudo. Nos concretos se explora essa tensão, especialmente nos poemas de Augusto de Campos.

Mallarmé já apontara uma crise do verso e no prefácio a Um lance de dados, sugere, depois da negação - "nada”, um “quase”, "talvez uma arte”. É nessa zona de risco, entre a impossibilidade e a possibilidade, que se constroem os poemas de Carlos Ávila (2012) no livro Área de risco. Trabalham também entre o verbal e o visual, mais um lugar entre, que, explorando contradições, permite encontrar possibilidades de poesia, entre o sonoro, o verbal e o visual, uma linguagem que nega a palavra banalizada. A própria capa já apresenta visualmente a impossibilidade com um traço negro sobre o título, a expressão em branco Área de risco.

Os poemas exploram as aliterações que são também um jogo visual, como no poema "De repente", que lembra o "A uma passante", de Baudelaire: 
outro outono

som de sombras

vozes interrompidas

sinais apagados

(ibidem, p.25)

No silêncio da página em branco, traços sonoros: a palavra "esquina" do segundo verso se transforma em "esquiva" no final do poema, com "fim" escrito na vertical.

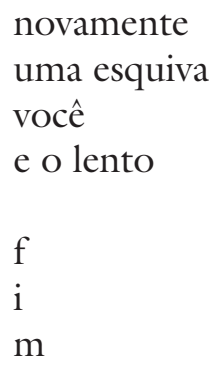

Mas a palavra vale aqui também na sua forma gráfica, como no poema YOU, construindo esculturas, talvez na busca de uma linguagem mineral como a pedra, fora da banalização da "linguagem reportagem", que já Mallarmé repudiava. Essa relação com a escultura aparece tematizada em "Talvez uma arte", em que se aproximam pedra e papel, lembrando com "anjos" e "trombetas" as esculturas de um Aleijadinho em Minas Gerais.

pedra

$\&$

papel

esculturas

de fazer

corar

os anjos

papel

\&

pedra

máscaras

de fazer

soar

trombetas

(ibidem, p.21)

Os poemas são mínimas tiras verticais, às vezes um verso é uma letra. Lembram alguns poemas de Sebastião Uchoa Leite, que se faziam também como tiras, e as experiências concretas de Augusto de Campos. Pede-se uma leitura 
noutra direção, não horizontal, mas vertical, como um ideograma, um hieróglifo; de qualquer modo, outro tipo de percepção. Lembram as figuras de Giacometti, os cenários de Beckett, com o mínimo, apresentando, pela negativa, uma recusa radical ao excesso do mundo do espetáculo. Também na contramão, a ideia de perder tempo, pensamentos, num universo em que o que está valendo é o "time is money".

perder tempo

segundos

minutos

horas a fio

desfiando

o nada

perder

-por exemplo -

pensamentos

pode ser poesia?

(ibidem, p.49)

Para Didi-Hubermann (1990), a arte tem consciência de que se faz com uma perda, tanto da representação habitual quanto das intenções conscientes. A imagem é sempre vestígio, traço de um apagamento "um operador visual de desaparição". O que fica como palavra da poesia também não seriam esses traços de um dilaceramento?

Lembrando as cantigas de escárnio e mal-dizer medievais que falam de um mundo bárbaro, aproxima-o do mundo da técnica (jamais fomos modernos, diz Latour), em que a ditadura da imagem e da usura transforma a vida em "vidadollars".

pululam

analfabetos:

a vida

em vídeo

ignorância

in english

(ânsia de ser

le dernier cri)

velocidade e ruído -

montaram assim

a sua bestética

valores 
(ávida dollars)

preferem o econômico

as burras

dos burros

cheias:

ouro podre

criaram assim

a ditadura

da imagem

e da usura

(Ávila, 2012, p.99)

Extremamente críticos, esses poemas são uma nova forma do trágico, apontando um mal-estar da cultura, num momento de espetacularização total, que atinge também a literatura. "Displaced" fala desse lugar de exílio que seria nossa condição num mundo globalizado, ou nossa condição humana mesma. Carpeaux falava de Kafka como a displaced person. Julia Kristeva (2005) fala de Celan como o poeta que nos diz dessa condição de sem lugar e que nunca poderia se encontrar com Heidegger que teima na habitação. Só nos resta errar e essa errância é poesia.

errar

a pé,

(sempre outro)

no mesmo

lugar

(Ávila, 212, p.89)

A natureza aparece como promessa, possibilidades que se abrem, mas num real que resiste à palavra, nos poemas "Sul da Bahia", e neste "Última estrofe" cabelos

embranquecem

mas ipês

(ainda)

florescem

(ibidem, p.53)

O texto inteligente da contracapa, de Ronald Polito, vê a divisão do livro em três partes - Linha de corte, Obstáculos e Área de risco - como um triplo movimento entre a poesia, a realidade e a subjetividade - que tentam, intercomunicando-se, apontar para o sentido de uma tentativa: "tornar de algum modo ainda possível a experiência humana".

Se a "Carta de Lord Chandos" fala da impossibilidade da linguagem verbal, outra carta de Hoffmansthal, a "Carta do retornado", fala de uma saída pelo visual, pela cor que o viajante encontra nos quadros de Van Gogh. Tempo e 
espaço fazem a poesia numa tradição do que Rancière chama de regime estético das artes. A condição trágica de alguém dilacerado de dúvidas se dá na aliteração “sem rumo / sem solução / sumo" (ibidem, p.15, "As feras”). O cenário é ruína, destruição, perda, naufrágio, que fazem a poesia de Mallarmé e Celan e Leopardi.

Área de risco traz uma poesia crítica, que se faz nessa tensão entre Eros e Tanatos, vida e morte, que, desencantada, no entanto, persiste. O poeta crítico desdobra sua reflexão no ensaio e aqui nos lembramos de seu livro Poesia pensada (Ávila, 2004), em que vai buscar Octávio Paz, outro poeta e crítico, teórico que reflete sobre a condição da poesia e do poeta hoje:

A arte que mais sofreu com o mercantilismo atual foi a poesia, obrigada a refugiar-se nas catacumbas da sociedade de consumo. Mas as outras formas literárias também foram prejudicadas, especialmente o romance, objeto de uma degradante especulação publicitária. Ante essa situação é saudável recordar que nossa literatura começou com um Não aos poderes sociais. A negação e a crítica fundam a idade moderna. (apud Ávila, 2004, p.20)

Outro poeta de que vou falar aqui é Duda Machado (2011) cujo novo livro Adivinhação da leveza me lembra o título do romance de Malcom Lowry, $A$ sombra do vulcão. Pois ao lê-lo a sensação que se tem é de que se está num lugar em que o equilíbrio é difícil, assentados sobre trepidações. A ênfase na sombra e não na claridade marca a procura de um outro tipo de pensamento, lembrando o verso de Paul Celan (1999, p.59, poema "Fala também tu"), "Fala a verdade quem fala a sombra". Duda Machado (2011), em Adivinhação da leveza, pensa nesse lugar inseguro, onde defrontamos os limites do conhecimento, lugar feito de ambivalências, paradoxos, tensionado entre o sentido e a falta deles "O que querias saber, não sabes / não sabes o que seria saber" (ibidem, p.37, poema "Enfim").

No poema "Sobre um velho tema" parece se delinear uma outra epistemologia: não há perguntas certas e respostas finais, mas a interrogação permeia a resposta e a própria interrogação se questiona

A interrogação que, ao descobrir

sua ânsia pela resposta,

atravessa o silêncio

e, refeita, retorna ao início

para indagar a si mesma.

A resposta que, a caminho de

estar pronta, refaz em silêncio

a distância que impôs a pergunta

e, de volta, injeta em si mesma

uma sintaxe interrogativa. (Machado, 2011) 
Já no livro Margem de uma onda (Machado, 1997), um poema sobre Novalis falava dessa busca de um outro pensamento. Contra a lógica do Iluminismo, que ordena e domina, o poeta romântico alemão articula um pensamento que chama de divinatório, pois liga sensibilidade e intelecto, na imaginação produtiva, que é a própria arte. Os primeiros românticos alemães, críticos da Revolução Francesa, que viam desembocar no terror, propunham uma transformação do pensamento. Só assim poder-se-ia mudar o mundo, mudando a maneira de pensá-lo. Novalis (1988, p.121), nos fragmentos de Pólen, diz que "nosso pensamento foi até agora seja meramente mecânico - discursivo, atomístico ou meramente intuitivo - dinâmico. Acaso chegou agora o tempo da unificação?”. Para ele, diferente do filósofo que apenas ordena, o poeta dissolve todos os elos - "suas palavras não são signos universais - são sons, palavras mágicas que movem belos grupos em torno de si”. Diz Duda Machado (1997, p.91) no poema "Fragmento para Novalis"

$[\ldots]$
a narrativa semelhante ao sonho
o caminho misterioso
sob a consciência
reconfigurado pelo verbo
em sequência de sons
que se representam
e parecem pairar
acima das palavras,
abaixo do entendimento
até que, à distância
entre fragmentos aflore
uma semântica submersa

No novo livro a proposta é essa reviravolta, dizer a sombra e a leveza, apenas adivinhada, uma outra partitura, em que ilusão e esclarecimento convivam, deixando ver o solo trepidante, a oscilação, os sobressaltos, o tremor do mundo sobre o qual a poesia se inscreve. Abre com um convite a uma viagem ao "Ermo das palavras", mas sem uma volta com explicações e a uma aceitação do impasse que é uma recusa do extraordinário, mas com "o incessível a proclamar sua companhia". Não se propõem metafísicas, mas uma aceitação dos limites do conhecimento. Lembramos as discussões de um cientista como Paul Feyerabend $(1984,1997,2011)$ que, em vários livros, faz uma crítica ao pensamento científico, de sua arrogância, sua autoridade no mundo contemporâneo, e defende uma ciência como arte. Não no sentido explorado de domínio da criatividade, mas de crítica ao mito científico da objetividade e à ideia de progresso, pois em arte só se pode falar de mudanças. Diz que talvez a separação entre ciência e sociedade constitua a única possibilidade que teremos de sobrepujar o barbarismo febril de nossa era técnico-científica, atingindo a humanidade que está ao nosso alcance, mas que jamais concretizamos inteiramente. Teríamos que assumir a 
ciência como uma tradição entre outras tradições de pensamento e dentro dela a insuficiência dos conceitos. O conhecimento não é só complexo, mas de uma natureza totalmente outra que um conceito matemático. Feyerabend busca uma ciência que acate a sensibilidade e mostra como certas teorias se construíram, levando em conta acasos e intuições. Teóricos como Castoriadis, Bruno Latour e outros fazem, desde alguns anos, a crítica da pretensão científica de esgotar o conhecimento.

Já em Margem de uma onda (Machado, 1997), o poema "Condição" propunha um outro tipo de conhecimento:

Conhecimento, seja.

Mas sempre tão recente

que apenas se desprende

do não conhecimento

Algo se esquiva ao conhecimento e ao mesmo tempo dele nos acercamos por uma colocação em questão constante, como no poema "Autoretrato":

$\mathrm{O}$ autoretrato indaga

o que de dentro do expor-se

a ele mesmo se esquiva

A relação sujeito/objeto no conhecimento é problematizada pelos primeiros românticos. Tanto sujeito como objeto estão em constante autorreflexão. Voltando a poemas do primeiro livro Crescente (1990), essas questões já estão lá, mesmo que pareça um momento inicial de libertar as palavras (especialmente no livro incluído Zil, de 1977, em que há um diálogo com os poetas concretos e o Mallarmé de Um lance de dados). No poema "Juntos", por exemplo, observado e observador, por um instante, estão unidos por uma luz que apaga superfícies, contornos de objeto e sujeito, da paisagem e daquele que a contempla:

o horizonte é a luz

que em cor tão unânime

apaga as superfícies

de que vive

esta paisagem

é só sopro

de um instante-abismo

que apenas há

ei-los depois

recém-nascidos,

já se respiram:

contemplador,

horizonte,

céu e mar. 
Também nesses poemas não é o tempo linear que importa, mas o instante, o agora que pode libertar também do peso da memória.

A poesia aqui é um ato cognitivo, mas que provém de um outro tipo de pensamento, em que "sim" e "não" convivem, deixando ver a hesitação, a ambivalência, a vacilação com que se constrói. Poesia aqui é coisa mental, mas num livre jogo entre sensibilidade e intelecto como diz Schiller ser toda arte. Traços de representação estão presentes, paisagens e lugares como em "Bar Santa Cecília": o bar com tevê e ventilador, com a trepidação do viaduto ao lado:
A tevê, o ventilador
fixado no alto
da parede ao fundo;
o metal amassado
do balcão, cuja limpeza
surpreende; a mulher
gorda, de gola alta
com quem ninguém
se atreve a brincar
$[\ldots]$
- continua, pertinente -,
um resto de trepidação
que vem do viaduto
ao lado.
(p.17)

Discutindo o humanismo, Edward Said (2007, p.31) diz que se podem adquirir filosofia e conhecimento, mas a falibilidade basicamente insatisfatória da mente humana (em vez de seu constante aperfeiçoamento) ainda assim persiste. Lembra Vico, afirmando que uma das principais razões que o levaram a escrever seu livro foi contestar a tese cartesiana de que seria possível haver ideias claras e distintas e de que estas estavam livres não só da mente real que as possui, mas também da história. Precisamos desmantelar as representações pré-fabricadas pelas quais somos bombardeados, para retomar o pensamente. Adorno diz que, com a indústria cultural, as palavras são violentadas e passam apenas a designar. Precisamos fazê-las voltar a significar. As palavras em liberdade, suspensos os elos e os sentidos coagulados que as uniam, articulam outras semânticas. No poema de Duda Machado, as palavras "tevê", "ventilador", "trepidação" e "viaduto" falam do mundo do progresso, da mídia e da ameaça de catástrofe que armam a cena contemporânea. Os dois poetas brasileiros trabalham com leveza e risco, articulando um outro pensamento que se faz necessário para descobrir, constituir ou adivinhar outras possibilidades no real. 
Referências

ÁVILA, C. Poesia pensada. Rio de Janeiro: 7letras, 2004.

Área de risco. São Paulo: Lumme, 2012.

CELAN, P. De limiar em limiar. Trad. Claudia Cavalcanti. São Paulo: Iluminuras, 1999.

DIDI-HUBERMAN. Devant l'image. Paris: Les Éditions de Minuit, 1990.

FEYERABEND, P. Contra o método. Rio de Janeiro: Livraria Francisco Alves, 1977.

Wissenschaf als Kuns. Frakfurt: Suhrkamp, 1984.

A ciência em uma sociedade livre. São Paulo: Editora Unesp, 2011.

KRISTEVA, J. Celanie. In: La haine et Le pardon. Paris: Fayard, 2005.

MACHADO, D. Margem de uma onda. São Paulo: Editora 34, 1997.

. Adivinhação da leveza. Rio de Janeiro: Azougue Editorial, 2011.

MALlaRMÉ, S. Mallarmé. Org. trad. e notas de Augusto de Campos, Décio Pignatari e Haroldo de Campos. 3.ed. bilíngue. São Paulo: Perspectiva, 1991. Coleção Signos.

NOVALIS. Pólen. Trad. Rubens Rodrigues Torres Filho. São Paulo: Iluminuras, 1988.

SAID, E. Humanismo e critica democrática. Trad. Rosaura Eichenberg. São Paulo: Cia. das Letras, 2007.

VILA-MATAS, E. Bartleby e companhia. Trad. Maria Carolina de Araújo e Josely Viana Baptista. São Paulo: Cia. das Letras, 2010.

RESUMO - O artigo trata de dois poetas contemporâneos que na sua linguagem procuram um outro tipo de pensamento, que articule outras possibilidades de real. Críticos da realidade tal como está estruturada no mundo contemporâneo, sua poesia é interrogação e questionamento.

Palavras-Chave: Poesia, Pensamento, Conhecimento, Sombra, Dilaceramento, Vestígios.

ABSTRACT - The article takes up two contemporary poets, whose language seeks a different kind of thinking - one that that articulates other possibilities of reality. Critics of reality as configured in the contemporary world, their poetry is interrogation and questioning.

KErWORDS: Poetry, Thought, Knowledge, Shadow, Distress, Remains.

Vera Lins é professora da Faculdade de Letras da Universidade Federal do Rio de Janeiro (UFRJ), com vários livros publicados, entre eles O poema em tempos de barbárie e outros ensaios (Eduerj; Faperj, 2013) e Poesia e critica: uns e outros (7Letras, 2005). @ - vl.lins@uol.com.br

Recebido em 5.1.2015 e aceito em 10.1.2015.

I Faculdade de Letras, Universidade Federal do Rio de Janeiro, Rio de Janeiro/RJ, Brasil. 
